\title{
Apology Strategies in Qassimi Arabic
}

\author{
Lina I. Alrshoudi \\ Department of English Language and Translation, College of Arabic Language and Social Studies, Qassim University, \\ Buraydah, Saudi Arabia
}

\begin{abstract}
This study aims to discover what types of apology strategies are utilized by Qassimi speakers. To achieve this, the data were collected by observations $(n=34)$ where apology speech acts were produced. All the participants $(n=53)$ are Qassimi Arabic speakers (a variety of Najdi Arabic spoken in central Saudi Arabia) as their L1. The data were analyzed according to Blum-Kulka's framework of apology strategies. The findings showed that Qassimi Arabic speakers used a range of apology strategies. Principally, they used a combination of illocutionary force indicating devices (IFIDs) and explanations of the reason for their apology. Besides, a range of alternative apology strategies was also evident; namely, using explicit expressions (only IFIDs), denying/taking responsibility, offering repair, and the promise of forbearance. Moreover, another novel apology strategy was also evident that has not been addressed previously in the literature; namely, where a victim apologies to an interlocutor who has offended them. These strategies differed in their popularity among the participants. The present study makes several noteworthy contributions to the field of pragmatics in general and the speech act of apology in particular.
\end{abstract}

Index Terms—apology, apology strategies, Qassimi Arabic, Qassimi speakers, speech acts

\section{INTRODUCTION}

Culture is a key factor that determines how speakers produce and perceive utterances. Thus, cultural awareness is essential to achieve successful communication. The production and interpretation of utterances are influenced by speakers' assumptions and expectations about interlocutors, interlocutors' actions, and the situations in which a dialogue takes place (Nureddeen, 2008). Therefore, our choice of linguistic expressions to achieve effective communication is based on the dominant speech community's cultural norms and conventions. In addition, context plays a crucial role in producing and perceiving communicative events (Swan, 1990, as cited in Nureddeen, 2008).

In our daily lives, we perform a range of different speech acts via verbal communication, such as promising, instructing, and apologizing. Apologizing, as one of the most frequently used speech acts, is found in all human languages and cultures (Farashaiyn \& Amirkhiz, 2011) and represents a reaction by someone who has committed a social offence against another (Blum -Kulka, House \& Kasper, 1989). However, as speakers tend to use a range of different expressions to express their apologies, therefore, their apology speech acts also differ.

Investigating how speakers apologize has great importance since how an apology is formed can reveal the cultural norms and conventions of a specific society. Indeed, apologies are crucial in maintaining harmonious social relationships (Jassim, 2016) and open the possibility for successful future communication.

\section{A. Previous Studies}

We now provide a critical review of six relevant studies in the related literature on apology strategies. Each of these studies deals with a specific variety of Arabic; namely, Sudanese, Tunisian, Jordanian, Iraqi, Algerian, and Najrani Arabic, respectively.

First, Nureddeene's (2008) study investigated the apology strategies used in Sudanese Arabic. The participants $(\mathrm{n}=110)$ were all educated adults resident in the Khartoum area. They were asked to respond to ten different situations involving social offence using a discourse completion task (DCT). The findings suggested that IFIDs and explanations were used more often in situations that involved less serious offences. However, as mentioned above, as each society has different norms on what is defined as taboo or socially offensive, it may be difficult to relate these findings to the present study's context of the Qassimi speech community.

Second, Jebahi (2011) also studied apologies by investigating how Tunisian university students formulate apology speech acts. The participants $(\mathrm{n}=100)$ were Tunisian Arabic native-speaker university students and a DCT was used to collect the data. The findings showed that statements of remorse were the most frequently used apology strategy when the person offended was a close friend, an elder, and/or had the authority to affect the future of the person committing the social offence. Furthermore, in many cases, the Tunisian participants denied responsibility for the perceived offence. The least used strategies were offer of repair, intensification, minimization, and blaming the victim. Although this study shares common ground with the present study in studying apology speech acts, the extent to which the interlocutors in the present study have an ability to affect the future of the person giving the apology differs.

Third, a study by Banikalef, Maros, Aladdin, and Al-natour (2015) examined the use of apology speech acts in Jordanian Arabic. Data were collected through observation based on a corpus of 1100 apology speech acts. This study also examined how contextual factors influence the choice of apology strategies. The findings showed that the most 
common apology strategy used among Jordanian speakers was acknowledging responsibility. Furthermore, a combination of apology strategies such as acknowledging responsibility and swearing by God's name were used frequently.

Fourth, in a study on the apology strategies used by Iraqi Arabic speakers, Muzhir and Raheem's (2012) study was mainly concerned with the gender differences in speakers' use of apology speech acts. The researchers used a DCT to elicit apologies from a sample of randomly selected participants $(\mathrm{N}=30$; males $=15$; females $=15)$ who were asked to respond to three different apology situations. The results indicated that Iraqi males frequently tend to promise repair to the victim when they are required to make an apology while Iraqi females mostly use compensation strategies to apologize. The results also revealed that Iraqi speakers express their apologies by using several strategies such as explicit apology, providing justification, describing the damage, promising not to repeat the offence, admitting responsibility, and thanking as a form of gratitude.

Fifth, Dendenne (2017) employed natural semantic metalanguage (NSM) and cultural scripts (CSs) ${ }^{1}$ to study the production of two speech acts - requests and apologies - among speakers from Arabic and English cultures. The findings are based on two groups from two cultures: Algerians $(n=32)$ and Anglo-Americans $(n=20)$. The Algerians were asked to respond to imaginary request and apology situations. In their apologies, the Algerians favoured claiming responsibility when he/she apologized to higher-status interlocutors, strangers, and a person to whom they had committed a serious offence. The research indicated that Algerian Arabic speakers prefer to claim responsibility because they treat each other on the basis of public availability. However, the Algerian Arabic speakers also tended to use explanations instead of admitting responsibility for committing a gross disservice to a close friend. The researcher interpreted this finding, saying, "A close friend is someone who is likely to tolerate our mistakes" (Dendenne, 2017, p.13). The findings also revealed that the use of intensifiers ${ }^{2}$ with certain apology strategies instead of IFIDs is part of Algerian culture. Finally, the participants tended to include the offended party in repairing the situation by including the victim in solving the issue or placing part of the responsibility on him/her (the victim).

Finally, a recent study by Alsulayyi (2016) investigated apology strategies employed by Najrani speakers teaching EFL in Saudi schools. The Najrani dialect is one variety of Janoubi Arabic spoken in southern Saudi Arabia. This study took a number of variables into account: social distance, severity of offences, and gender. To explore what apology strategies the Najrani teacher participants $(n=30)$ used, the researcher employed a DCT with ten apology situations that required the participants to imagine a series of perceived offences and react to them. The findings showed that using IFIDs was the most frequent apology strategy used by the Najrani EFL teachers. The findings also revealed that the respondents used several other strategies such as minimizing responsibility, offering repair, and claiming responsibility.

In summary, although the above-mentioned studies investigate a wide range of Arabic speakers' use of apology strategies, to the best of the researcher's knowledge, there are no studies on Qassimi Arabic speakers' use of apology strategies. Therefore, the present study attempts to fill this research gap and provide insights into the apology strategies used by Qassimi Arabic speakers. This study is significant because it represents the first attempt to examine how Qassimi speakers perform apology speech acts. This study addresses the following research question:

What apology strategies do Qassimi Arabic speakers use in a range of different apology situations?

\section{B. Qassimi Arabic}

The Qassimi dialect is an Arabic dialect spoken by nearly 931,085 people in the AlQassim region of Saudi Arabia. Located in the Najd territory in central Saudi Arabia, the AlQassim region is divided into 11 provinces whose members speak the same dialect albeit with minor differences. This variety of Arabic has maintained its local features due to its isolated geographical location as it has little contact with the borders of Saudi Arabia (Alrashed, 2018). This region preserves some of Standard Arabic's dialectal phenomena and has several unique features. One of the most prominent features is that Qassimi speakers tend to facilitate their pronunciation by producing syllable units in the most straightforward way possible (Shitaa, 2020). For example, Qassimi speakers often replace / / with /a/; for instance, in the middle of /bartoha:/ (her house); and they tend to omit the /a/ finally to facilitate easier pronunciation.

\section{THEORETICAL FRAMEWORK}

This section presents the study's theoretical foundation, which determines the data analysis approach described later.

\section{A. Speech Acts}

Speech acts are actions performed by a speaker via the act of verbal communication (Kroger, 2018). Speech act theory was introduced by Austin (1962) in his influential work How to Do Things with Words. Austin asserted, "there is a lot more to a language than the meaning of its words and phrases" (Thomas, 2013, p.31). By this, Austin meant that

\footnotetext{
${ }^{1}$ Wierzbicka developed NSM with to provide a system that represents all meanings in all languages based on a set of semantic primes (SPs). NSM includes a combination of SPs and syntactic structures (LÖbner, 2013). SPs are basic vocabulary that are common in all languages (Goddard \& Wierzbicka, 2007). These expressions are merged into sentences to demonstrate certain concepts or phenomena (LÖbner, 2013). The technique of formulating cultural behaviors, norms, and values in a way that is accessible to insiders and outsiders of a certain culture is called cultural scripts (CSs) (Goddard \& Wierzbicka, 2004).

${ }^{2}$ Intensifiers are modifiers that express honesty in apologies, such as swearing (Dendenne, 2017).
} 
we do not simply use a language to state something (e.g. to comment on the temperature of a hot room); rather, we use language to perform actions (e.g. in the case of the previous example, to direct our hearer to open a window). Thus, Austin proposed three components to communication: (a) locutionary acts (the act of uttering something), (b) illocutionary force (the act the speaker wishes the hearer to perform), and (c) perlocutionary effect (the effect of the utterance on the hearer) (Kroger, 2018).

\section{B. Direct Speech Acts and Indirect Speech Acts}

A direct speech act is the one that is inferred directly from the literal meaning of an utterance (Kroger, 2018). For example, when someone says "I apologize for interrupting you", he /she explicitly expresses his/her apology. Verbs like apologize are called performatives (Austin, 1962), since by uttering them, they perform 'actions' that cannot be judged as either true or false (Thomas, 2013).

However, speech acts that require the hearer/reader to derive their meanings from the actual words spoken are called indirect speech acts, the meaning of which are inferred by implicature (Kroger, 2018). For example, if one says 'I didn't mean it!" to someone we have offended, we actually intend to apologize implicitly.

\section{Apology}

An apology is a post-event speech act performed by an apologist with the intention of effecting a remedy for the perceived offence (Blum-Kulka et al., 1989; Holmes, 1989). By apologizing, the speaker admits that he/she has violated social norms (Blum-Kulka \& Olshtain, 1984). In addition, the offender demonstrates that they take responsibility for their insult and express his/her regret (Fraser, 1981, as cited in Nureddeene, 2008). Therefore, apologies involve a loss of speaker's 'face' and provide support for the hearer (Blum-Kulka \& Olshtain, 1984). Indeed, as we mentioned above, "The ultimate purpose behind acting apology is to maintain harmony and avoid conflict in relationship with other people in everyday communication" (Spencer-Oatey, 2008, as cited in Jassim, 2016, p. 1).

\section{Apology Strategies}

Cohen and Olshtain (1981) were among the first to investigate apology strategies using DCTs. DCTs are used to collect data from participants by asking them to respond to certain situations in which they are required to perform a particular speech act, such as apologizing, thanking, asking, requesting, etc. (Kitao \& Kitao, 2013). According to BlumKulka et al. (1989), the act of apologizing can be performed in terms of three basic strategies:

1. Explicit expression of apology (using IFIDs, such as being sorry, apologizing, expressing regret, giving an excuse, asking to be forgiven, etc.). A speaker uses such devices to signal regret and appease the hearer; ultimately, he/she accepts the need to apologize (Kitao \& Kitao, 2013).

2. Implicit expression of apology (without IFIDs) including the five sub-categories as follows:

a. Taking responsibility for committing the offence (e.g., I am forgetful).

b. Denying the offence when the reasons are not related to the apologist's offence (e.g., It is not my fault that it broke).

c. Explaining the cause of the fault (e.g., The flight is delayed).

d. Offering repair (e.g., I will fix it).

e. Promising that the offence will not happen again (e.g., I promise I will not do that again).

3. Apologies accompanied by an IFID to achieve intensification (e.g., I am very sorry). An apologist uses intensifiers to strengthen his/her apology (Kitao \& Kitao, 2013). The use of intensification is particularly used by those with lower status to express the sincerity of their apology (Olshtain, 1989).

On a different tack, an offender may sometimes attempt to minimize the seriousness of their offence as a strategy of apology. For example, they may say something like "You are just over sensitive" (Olshtain, 1989, as cited in Kitao \& Kitao, 2013). Also, apologists sometimes provide justification for their actions; e.g., "I'm sorry for not helping you in carrying your bags, but they are too heavy" (Kitao, 2012, as cited in Kitao \& Kitao, 2013).

According to previous studies, IFIDs and taking responsibility appear to be available apology strategies in many different languages. However, the differences among the specific apology strategies used are based on the specific situation and culture in which they are used (Salago 2011, as cited in Kitao \& Kitao, 2013).

Finally, some evidence exists of speakers using a combination of two apology strategies; for example, combining explicit and implicit expressions: "I am sorry but I have had an accident".

\section{MethodolOGY}

This section outlines the research method chosen to examine Qassimi Arabic speakers' apology speech acts.

\section{A. Participants}

The data were collected from a randomly selected sample $(n=53)$ of Qassimi Arabic native speakers.

\section{B. Instrument}

Most previous research on apology speech acts uses DCTs as the main data-collection instrument. However, this use of DCTs has been criticised by Nurani (2009, as cited in Banikalef et al., 2015) because data collected via DCTs are 
considered as unnatural since DCTs necessarily involve imaginary (i.e. not real-life) situations. Therefore, ethnographic observation has been suggested as a solution since it provides real insight into apologizing in natural communication (Blum-Kulka et al., 1989; Hymes, 2003; Trosborg, 1994, as cited in Banikalef et al., 2015). Thus, the present study uses direct observation to investigate Qassimi speakers' apology speech acts in a range of different situations.

\section{Collection and Analysis of Data}

This study is based on apology utterances $(n=34)$ in spoken Qassimi Arabic, collected via direct observations. The data were produced by Qassimi Arabic speakers $(n=53)$ of different ages all of whom were born and grew up in the AlQassim region. Using Blum-Kulka's framework, the researcher observed 34 apology speech acts over 43 days that took place in real-life settings such as university campuses, domestic settings, malls, and on social media (WhatsApp, Twitter, Snapchat, Instagram, etc.).

\section{RESULTS}

This study investigated the apology speech act strategies Qassimi Arabic speakers used in different real-life apology situations. The results revealed that the participants performed apology speech acts using seven different strategies in Blum-Kulka's framework as detailed below. The most common strategy used was a combination of explicit and implicit expressions, particularly strategies (1) and (2. c) in Blum-Kulka's framework. Another common strategy the Qassimi Arabic speakers used was performing an explicit apology (1 in Blum-Kulka's framework). Besides, there were several incidences of the Qassimi Arabic speakers taking responsibility (2.a in Blum-Kulka's framework), and admitting responsibility for the offence. In a few apology situations, the participants offered repair for the offence or damage (2. $d$ in Blum-Kulka's framework). Similarly, the strategy of denying responsibility (2. b in Blum-Kulka's framework) was rarely employed as was when the wrongdoer promised the victim that the offence would not be repeated (2. e in BlumKulka's framework). Interestingly, the findings also suggest that a new apology strategy not considered in previous studies was identified. Specifically, it was common that in many of the situations, the person offended actually apologized even though he/she was not the one who committed the offence.

\section{DISCUSSION}

The main purpose of this study was to investigate and explore the apology strategies used by Qassimi Arabic speakers in a range of different situations.

The participants often expressed their apology explicitly and provided an explanation of their violation. To explain, they explained why the offence happened, since they may assume that such an explanation would be sufficient to placate the hearer. Also, the participants combined IFIDs with their explanation to express the sincerity of their apology. The following example is an apology speech act that took place on WhatsApp:

A. /ænæ æsfəh mæ rəddeIt ৎ’leık, ænnєt kæn ta:fi/.

I am sorry for not replying to you, the network was not working.

Qassimi speakers also tended to use an explicit apology (1 in Blum-Kulka's framework) since they may believe that this would be sufficient to compensate the other party for the offence. An example of an IFID used by one participant is:

\section{B. /mæS'æleIf\%.}

I am sorry.

Based on this, we can say that Qassimi speakers tend to use similar apology strategies to Sudanese speakers (Nureddeen, 2008) since both often apologize by providing an explanation and using IFIDs (although Qassimi speakers often tend to combine these two strategies). The finding that using IFIDs is common among Qassimi speakers matches Alsulayyi's (2016) findings in which Najrani speakers often apologize explicitly. However, these results differ from Dendenne's (2017) where he found that Algerian Arabic speakers usually apologize by using intensifiers rather than IFIDs.

As the results show, it is clear that the strategies of taking responsibility and admitting responsibility for the offence are often used when the offended has authority over the person offering an apology. An example of this strategy is that when a student arrived late to class and interrupted the teacher, and then said:

\section{C. /mækənt ægsed/.}

I didn't mean it.

The results of this study are in line with Banikalef et al.'s (2015) who also reported that one of the most common apology strategies was acknowledging responsibility.

The strategy of offering repair for an offence or damage is not commonly used by Qassimi Arabic speakers. One possible explanation for this is that repairing damage cannot sometimes be achieved. The following example is a dialogue between two sisters, $\mathrm{X}$ and $\mathrm{Y}$, where $\mathrm{Y}$ had just broken $\mathrm{Y}$ 's cup:

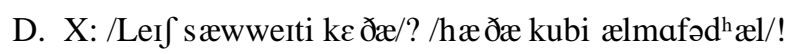


Why did you do that? It's my favourite cup!

Y: /læ tk ${ }^{\text {h }}$ æin/, /bədzib lets ḑedid/.

Don't worry, I'll bring you a new one.

Therefore, in terms of performing apology speech acts, Qassimi Arabic speakers tend to be similar to Tunisian Arabic speakers (Jebahi, 2011) in that they do not always offer repair when they offer an apology. However, this finding does not match that indicated by Muzhir and Raheem (2012), in which the strategy of offering repair is was the most-used apology strategy Iraqi Arabic speakers.

Besides, the findings revealed that the strategy of denying responsibility (2. $\mathrm{b}$ in Blum-Kulka's framework) was rarely used by Qassimi Arabic speakers. One explanation for this is that Qassimi Arabic speakers may believe that denying responsibility cannot remedy the offence. However, if denying responsibility is actually performed, the speaker may believe that he/she is not the cause of violation or maybe does not want to admit that he/she has actually offended the hearer (Nureddeene, 2008). The following provides an example where tow friends, A and B, plan to go to the park together. However, B has arrived late:

\section{E. A: /Tæ $æ æ k^{\mathrm{h}} \mathrm{rti}$ mærrəh/.}

You are too late.

B: /Mab bidi/.

It was not up to me.

Hence, the findings show that Qassimi Arabic speakers differ from Tunisian Arabic speakers as the former infrequently deny responsibility when they apologize, while the latter often assume responsibility.

In accordance with the strategy of promising not to repeat the offence, the Qassimi Arabic speakers performed this strategy on very few occasions since they may believe that it would threaten their positive face ${ }^{3}$. As Nureddeen (2008) pointed out, "expressions of forbearance threaten positive face and are therefore avoided" (p. 291). An example of this strategy is that when a child broke his mom's iPhone, saw her anger and said:

\section{F. /Mæmæ/, /hæði æk $\mathrm{k}^{\mathrm{h}}$ r mərrəh æswwi kєðæ/.}

Mom, this is the last time I will do that.

As mentioned above, the most interesting finding is that the Qassimi Arabic speakers also performed apologies by utilizing a new strategy not mentioned in the previous literature. Specifically, the victim performs an apology instead of the offender despite the victim not being the one who has committed the offence. This can be explained by the fact that the victim appears to wish to avoid conflict with the offender. Therefore, he/she apologizes to prevent an argument from developing and thus avoiding conflict. However, this apology strategy can be considered insincere. For example:

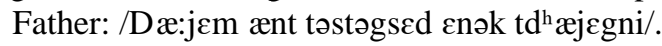

You always intend to bother me!

Son: /æsef/, /lək ælhæg təhufən/.

I'm sorry, you have the right to scold me.

Consequently, the Qassimi Arabic speakers investigated in this study used a range of different apology strategies. Thus, we can say that there is diversity in the use of apology strategies by Qassimi Arabic speakers as well as among speakers of the other varieties of Arabic. Therefore, speakers of different Arabic dialects appear to select their choice of apology strategy based on the specific cultural norms surrounding apologising. However, due to time constraints, this topic is beyond the scope of this study and represents an interesting area for future research.

\section{CONCLUSION}

The present study investigated the apology strategies used by spoken Qassimi Arabic speakers. This study was based on real-life situations where apologies were performed and the data were collected via ethnographic observation. The most obvious finding to emerge from this study is that Qassimi Arabic speakers use several different strategies to express their apologies; the most common strategy is apologizing by using both explicit and implicit expressions. In many cases, using only IFIDs was also a common strategy among the participants. Moreover, denying responsibility or taking responsibility was also used. In a few situations, offering repair and promising forbearance were utilized. In addition, the findings showed that the participants used a strategy not mentioned previously in the related literature; namely, insincere apology. This finding could provide grounds for future research into the use of this strategy among Qassimi Arabic speakers. These findings are considered valuable as they were gathered from naturally occurring apology performances and they explore the key cultural conventions associated with apology strategies used by Qassimi Arabic speakers. However, the current study is limited by the short duration of the observations and the data were collected by the researcher alone rather than by a panel of researchers, which may have added more validity to the results. Therefore, future research with a longer duration is required to more extensively explore the apology strategies used by Qassimi Arabic speakers. Moreover, relying on a single data collection instrument (ethnographic observation) is a further limitation of this study. Future research could make use of a mixed-methods approach including both

\footnotetext{
${ }^{3}$ Positive face is an individual's need to be liked or accepted (Thomas, 2013).
} 
qualitative and quantitative data collection instruments such as DCTs and semi-structured interviews to enhance reliability and identify key themes and important findings.

\section{APPENDIX}

Data Collection Form

1. Situation:

2. The exact words that an apologist used to apologize:

\section{ACKNOWLEDGEMENTS}

The author would like to thank her professor, Dr. Bader Alharbi, for his encouragement and helpful comments.

\section{REFERENCES}

[1] Alrashed, A. S. (2018). Descriptive analysis of Qassimi Arabic: Phonemic vowels, syllable structure and epenthetic vowels, and affrication. ProQuest Dissertations Publishing, 1-100. Retrieved in October 2020 from https://search-proquestcom.ezproxy.qu.edu.sa/docview/1698103976?pq-origsite=summon.

[2] Alsulayyi, M. N. (2016). Apology strategies employed by Saudi EFL teachers. Advances in Language and Literary Studies, 7(6), 70-83. doi:10.7575/aiac.alls.v.7n.6p.70.

[3] Austin, J. L. (1962). How to Do Things with Words. Oxford: Oxford University Press.

[4] Banikalef, A. A., Maros, M., Aladdin, A., \&amp; Al-natour, M. (2015). Apology strategies in Jordanian Arabic. Journal of Language Studies, 15(2), 83-99. Retrieved in August, 2020 from journalarticle.ukm.my/8871/1/7203-25669-1-PB.pdf.

[5] Bataineh , R. F., \& Bataineh, R. F. (2008). A cross-cultural comparison of apologies by native speakers of American English and Jordanian Arabic. Journal of Pragmatics, 40(4), 792-821. doi:10.1016/j.pragma.2008.01.003.

[6] Blum-Kulka, S., House, J., \& Kasper, G. (1989). Cross-cultural pragmatics: Requests and apologies. Norwood, NJ: Ablex.

[7] Blum-Kulka, S., \& Olshtain, E. (1984). Requests and apologies: A cross-cultural study of speech act realization patterns (CCSARP) ${ }^{1}$. Applied Linguistics, 5(3), 196-213. https://doi.org/10.1093/applin/5.3.196.

[8] Cohen, A. D., \& Olshtain, E. (1981). Developing a measure of socio- cultural competence: The case of apology. Language Learning, 31(1), 113-134. Retrieved in October 2020 from https://doi.org/10.1111/j.1467-1770.1981.tb01375.x.

[9] Dendenne, B. (2017). A cross-cultural study of speech act realisations in Arabic and English: A cultural-scripts approach. Revue Académique Des Études Humaines Et Sociales, (18), 3-15. doi: 10.33858/0500-000-018-053.

[10] Farashaiyn, A., \& Amirkhiz, S. Y. (2011). A descriptive-comparative analysis of apology strategies: the case of Iranian EFL and Malaysian ESL university students. English Language Teaching, 4(1), 224-229. Retrieved in September 2020 from https://files.eric.ed.gov/fulltext/EJ1080324.pdf.

[11] Goddard, C., \& Wierzbicka, A. (2004). Cultural scripts: What are they and what are they good for? Intercultural Pragmatics, 1(2), 153-166. doi:10.1515/iprg.2004.1.2.153.

[12] Goddard, C., \& Wierzbicka, A. (2007). Semantic primes and cultural scripts in language learning and intercultural communication. In F. Sharifian \& G. Palmer (Eds.), Applied cultural linguistics (pp. 105-124). doi:10.1075/celcr.7.08god.

[13] Holmes, J. (1898). Sex differences in apologies: One aspect of communicative competence. Applied Linguistics, 10(2), $194-213$. doi: 10.1093/applin/10.2.194.

[14] Jassim, A. H. (2016). EFL Arab students' apology strategies in relation to formality and informality of the context. Ampersand, 3,117-125. Retrieved in September 2020 from https://doi.org/10.1016/j.amper.2016.06.001.

[15] Jebahi, K. (2011). Tunisian university students' choice of apology strategies in a discourse completion task. Journal of Pragmatics, 43(2), 648-662. doi:10.1016/j.pragma.2010.09.008.

[16] Kitao, S. K., \& Kitao, K. (2013). Apologies, apology strategies, and apology forms for non-apologies in a spoken corpus. Journal of Culture and Information Science, 8(2), 1-13. Retrieved in September 2020 from https://doors.doshisha.ac.jp/duar/repository/ir/23120/039000100001.pdf.

[17] Kroeger, P. R. (2018). Analyzing meaning: An introduction to semantics and pragmatics. Berlin: Language Science Press.

[18] LÖbner, S. (2013). Understanding semantics. London and New York: Routledge.

[19] Muzhir, H. D., \& Raheem, M. A. (2012). A Socio-pragmatic study of apology in Iraqi non-standard Arabic. University of Kufa: UOK Journal Hosting Service, 1(12), 65-86. Retrieved in September 2020 from https://core.ac.uk/download/pdf/235686990.pdf.

[20] Nureddeen, F. A. (2008). Cross cultural pragmatics: Apology strategies in Sudanese Arabic. Journal of Pragmatics, 40(2), 279306. doi:10.1016/j.pragma.2007.11.001.

[21] Olshtain, E. (1989). Apologies across languages. In S. Blum-Kulka, J. House, \& G. Kasper (Eds), Cross-Cultural Pragmatics: Requests and Apologies (pp. 155-174). Norwood, NJ: Ablex.

[22] Shitaa, J. M. (2020). Phonological development in the dialect of Qassimi people based on the theory of easiness and facilitation. $\begin{array}{lllll}\text { Wayback } \quad \text { Machine, 2376-2432. } & \text { Retrieved } & \text { October } & \text { from }\end{array}$ https://journals.ekb.eg/article_9556_0c455c315f440daf518db0200905999f.pdf.

[23] Thomas, J. (2013). Meaning in interaction. New York: Routledge. 
Lina I. Alrshoudi received her B.A. degree in English Language and Translation from Qassim University, Buraydah, Saudi Arabia in 2017. She is currently a master's candidate in Theoretical Linguistics at Qassim University, Department of English Language and Translation, Buraydah, Saudi Arabia. 